\title{
Adopting an African Standpoint in HCl4D: A Provocation
}

\section{Muhammad Sadi Adamu}

School of Computing and Communications,

Lancaster University, UK.

m.adamu@lancaster.ac.uk
Permission to make digital or hard copies of part or all of this work for personal or classroom use is granted without fee provided that copies are not made or distributed for profit or commercial advantage and that copies bear this notice and the full citation on the first page. Copyrights for third-party components of this work must be honoured. For all other uses, contact the owner/author(s).

CHI 2020 Extended Abstracts, April 25-30, 2020, Honolulu, HI, USA

(C) 2020 Copyright is held by the owner/author(s).

ACM ISBN 978-1-4503-6819-3/20/04.

DOI: https://doi.org/10.1145/3334480.3382833

\begin{abstract}
While studies in HCI4D have been advanced by the shift of perspective from developmental studies to a range of other discourses, current analytical concepts for understanding the sociality of society in Africa have arguably led to some misinterpretations of the place of technology. This provocation suggests that an 'African Standpoint' based on a combination of various standpoint positionalities and the Wittgensteinian approach of Winch can offer conceptual and analytical sensitivities for articulating social relations,

transnational engagements and the conceptualisation of technological innovation. This provides an approach for seeing and accounting for things as they are - right here, right there and right now - and not some idealised conception of an African reality.
\end{abstract}

\section{Author Keywords}

Africa; HCI4D; standpoint; provocation; enlightenment

\section{CCS Concepts}

Human-centred computing $\sim \mathrm{HCI}$ theory, concepts and models

\section{Introduction}

To begin with a provocation, one might argue that the general concept of HCI4D debate in computing has been two sides of a coin, one ideological and the other utopian [9, 32]. Critically analysing its current discourse might suggest discovering the former but 
covering the latter. However, the partitioning of $\mathrm{HCI}$ to particular histories, experience and social context has begun to widen our understanding of technology in society [30]. Also, the surge in multicultural and technocultural relations and the complexities of historical and emerging forms of power relations have instead brought about a continuation of domination under the rubric of 'development' [16]. This necessitates elucidating the linguistic confusion already prevalent in HCI4D by examining the premiss that informs its concepts and methods within the social imaginary of Africa. This provocation signifies an epistemological and methodological vehicle for marginalised thoughts and voices. Not as a generality of the African reality, nor a commonality of circumstances, but a dialogue and a form of empowerment that places the underlying structure of social life central to the technological discourse.

\section{What the African Standpoint is(not) and Can be}

The foundation of 'the African standpoint' is about power, culture and knowledge. It is the possible outcome of an intellectual, social and political struggle towards a socially situated and objective understanding of the African tradition [11]. In HCI, it is a situated orientation, an epistemological positionality and an analytical pedagogy for moving from investigating and understanding culture and values into design [2]. It provides a set of sensitivities and a language for analysing technological innovation in the multi-cultural and multilinguistic context of Africa. In addition, the African standpoint is not a culture or linguistic theory [21], nor an extension of Feminist methodology - it can be. It is to be regarded as shared aspiration for moving towards the intellectual position and moral tradition exhibited of the Feminist HCI methodology [4]. It can also be regarded as a generative means of understanding and reporting of ourselves and others, either through the decolonisation of well-known methods or through unfamiliar one's that can be generated in our embodied actions and activities as creators and organisers of our social world.

\section{Context}

The provocation that the paper makes is not a criticism of associated theories and orientations that have advanced the debates about the place of culture and tradition in HCI4D but an epistemological and methodological debate concerning the grounding of familiar arguments to the practice of cross-cultural and intercultural design [29]. This is written not in ignorance of other alternatives like the Hofstede 'cultural dimension', Hall's model of 'beyond culture', and other models of appropriating technology. Instead it suggests that they oversimplify the central ideas of cultural differences and the complexities of traditions. The slippery debate about the differences and the universality of culture in design spaces are ones that examine the complexities of social identifiers, agency and location of culture [5]. Both models of 'cultural hybridity' [5], 'interculturality' [23], and 'culturally localised user engagement and empowerment' [29] are a means for bringing about a radical change in the conception of culture in worldly spaces. Such a movement, which the provocation identifies, locates culture in the relational praxis of oppression and struggle - as a transgressive option for critically analysing the 'in here' and the 'out there' [30], and also as an adaptive and inward praxis for transcultural engagement [41] and intercultural translations [16]. 
Human Computer Interaction for Development

The discourse about HCI4D has concerned understanding the implications of technology as a catalyst for the development of a range of social and economic conditions. The discourse first attempts at problematising $\mathrm{HCI}$ as a 'development' research in developing countries [32], and later move towards a nuance of a 'post-development' narrative [9]. The trajectory has shown that development is 'slow' and evaluated as a long-time 'outcome' of an innovation or result towards development goals. Whereas research attempts at producing something 'new' through the analysis of immediate result and 'output' [9]. The discourse also examines how a range of positionalities and cultural lenses can inform the framing, the analysis, and the design of technologies to be used in a range of communities. Even with the resentment towards colonial epistemological traditions and their associated theories and methodologies, researchers engage in merely adopting approaches without necessarily examining the assumptions that ground them. This might, inadvertently, lead to the misinterpretation of user's values into design, possible led to low adoption of tools, and might even lead to the misrepresentation of the implication of technology in such communities. Through the African standpoint philosophical perspective regarding the language concepts of understanding other culture and values, the paper situates and examines the 'social imaginaries' grounding a range of approaches that can be considered appropriate and relevant to the conceptual understanding of African realities. This is achieved through problematisation of the different theories, orientations, and cultural constructs that inform the practice of HCI4D in Africa.
Theories and Orientations Informing HCI4D

As technological innovation travels globally, the constructs informing the processes and practice of their production comes into contract with a range of entities. With the unequal flow and exchange of innovation, postcolonial $[17,21]$, decolonial $[3,7,33]$, and Afrocentric [39] positionalities have offered ways of defamiliarizing cultural relations and of analysing the specificity and universality of design practices in $\mathrm{HCI}$. However, such alternatives have often been characterised as analytical sensitivities that signify the unequal dichotomies of 'in here' and 'out there' [30], and which might present a danger of radical misinterpretations of culture. Others have examined how reframing dominant assumptions and traditions through indigenous perspective and experiences $[1,18$, 40] can bring about developing concepts and methods for understanding and designing for/with local communities. However, a closer examination into the theories informing these positionalities suggests how postcolonial (PC) and decolonial (DC) theories might have limit the interrogation of dominant traditions in the geopolitics of knowledge production. Some argue that PC lack's universal outlook [24, 34], silence local voices and delimit constructive dialogue [27], obscures other realities [13], and become silent on the complex issues of race and gender [22]. The DC option might similarly be considered under-theorised [31], heavily grounded in the geo-body politics of knowledge and the decolonial tradition [23] and thus limiting the analysis of geographical difference through its praxis and inquiry. In between the more prominent theories informing the HCI4D discourse in Africa, one can notice the lack of shared concepts of understanding (or even noticing) African realities and sociality. 


\section{Cultural Lenses Informing HCI4D}

Although the positioning of technology for/as a developmental apparatus has brought about a shift in perspective in $\mathrm{HCI}$, it has also repositioned some of the underlying ideologies of the field, specifically the homogenisation of various traditions in relation to Western epistemological traditions. The shared differences in culture and context are yet to provide a clear cut and distinctive understanding of 'local', 'global', or 'hybrid' practice [25]. Although a range of cultural lenses have shown how the differentiation and homogenization of culture through multiculturism, cross-culturalism, inter-culturalism can be problematic $[15,16,29]$, others have shown how indigenous paradigms $[39,41]$ can bring about a reflective means for articulating shared values and inspiration for cocreation. However, due to issues of power relations and the crisis of representation, one might begin to identify how the analysis of a multitude of situated practices can be difficult, problematic, and selective. Even in transcultural scenarios, one might question the power relations involved in identifying which value is to be considered and which is not. Instead, it is through the idea of a cultural asylum - as a spatial space for creation, dialogue, and restoration - that an adaptive mode of cultural engagement can be established.

\section{African Standpoint and HCI4D}

From the examination of the theories, orientations and cultural lenses informing the practice of the HCI4D community, I have attempted to problematise the concepts of understanding culture and values as applied to specific African concerns. It seems likely that current models do not provide the relevant concepts for understanding and characterising cultural motives, the hybridity of encounters, the relationality of reasoning, and the generality of human understanding. One might ask, which participant, value, culture, context, language and community? What are the power relations involved? What is at stake is the implications of naturalising dominant rules for the analysis of African identity and realities. This paper suggests that a standpoint positionality and the consideration of how understanding is embedded in the passage of prior realities and concerns might offer adaptive alternatives for intelligibly framing and analysing the understanding of people's culture and value for the purpose of design.

\section{Possibilities and Impossibilities of Understanding 'Other' Society - Wittgenstein and Winch}

One central idea from Wittgensteinian approach concern understanding the characterisation of human understanding of social life as embedded through models of rule-use and the use of language $[28,38]$. The emphasis is on how rules shape the reason for ordering social life, while language provides the motive for examining how previous histories provide passage and a pedagogy for the reasoning and disposition of linguistic confusion that provides an interpretive understanding of social interaction. To examine the basis for devising ways of developing critical and unbiased ideas about understanding a social phenomenon, the orientation argues for an understanding of the rules of language, in describing forms and modes of social life in Africa. It is evident that the politics of language in Africa take dual forms as a way of communication and as the root and carrier of culture. Wa Thiong ' $o$ ' [36] argues that culture, through language rules, reflects the articulation of our 
being and that of others, and acts as a means for understanding the imaginaries' of social life.

While the approach is not a recapitulation of tropes, of restating the difference between Western sensitivities with perhaps less developed ones, it is calling into question various ideas about cultural relativism; arguing instead for linguistic relativism as a misnomer for instances of cultural heterogeneity. With the uneven dynamic of power relations, the complexities of cultural and social differences might suggest a widening of the concepts of understanding the catalytical dimension of technology as a developmental apparatus. What the standpoint approach points to is the role of linguistic relativism in the epistemological and methodological debate about the underlying concepts of understanding other cultures -making the characterisation, differentiation, and universalisation of social experience through familiar and unfamiliar terrains open for both analysis and regeneration. This, therefore, brings about developing emerging concepts of understanding transnational collaboration and multicultural ideation, of analysing the rules guiding the forms and mode of social life, and of how their reformation might provide a form of characterising cultural generality. These ideas necessitate rethinking stereotypical concepts of understanding the implication of innovation 'out there' and 'in here' [30] and moving towards imagining the possibilities and impossibilities of empirical and rulebased abstractions.

\section{Situated Approaches to Knowledge}

The orientation builds on other, notably feminist, standpoint approaches. In feminist studies, intersectionality has been used as an analytical and conceptual tool for exploring issues of social inequality $[8,26]$. It is also a mechanism for untangling the complexities of the politics of identity and knowledge production. The approach grounds knowledge claims in the identity, mode of conceptualising reality, and the objective location of the knower [14]. It also brings about an analysis of the multitude of black identity, epistemic tradition, geographical locales, racial struggle, gender discrimination, and power relations. The approach shows how conventional forms of rationality and objectivity privileged certain positionalities, thoughts and experience over other's [8] - which needed to be reconsidered. This is important as it could show that the analysis of innovation in a cultural asylum is not concerned only with issues of crisis and politics of identity and knowledge, but also with how inequalities and injustice are manifested in the practices of analysing socio-technical concerns. In HCI4D, such an analytical sensitivity can provide a means for empowering situated identity, epistemic locale, and the self, while also being conscious of the plurality of perspectives and the network of differences in epistemologies and methodologies [4]. Such an outlook could provide a critical praxis for understanding the 'other', in their individual and collective voices, and through distinctive epistemologies that are relational to their lived conditions and realities.

\section{Translating Values and Local Meanings to Design}

In developing new and practical terrain, everyday mundane practices can be turned into rules for the conceptualisation of local meaning and indigenous practices and knowledge. The idea is of regarding how ordinary forms of social relations are embodied in discursive ideas, actions and activities; and of how such 
socially established concepts and multilinguistic narrative can form the basis for an African methodological development [38]. It emphasises the importance of articulating the complexities of difference in rules and ontological-epistemological worldviews and suggest how the heterogeneity of thought and experience of actors are to be voiced from the standpoint of the African social imaginaries. It also places the subtle requirement of examining how indigenous knowledge can be developed through the practice of imagining and making in both silence and aloud [20]; through to walking and asking [37], listening [35], and speaking [6]; and to walking in silence for the purpose of design. Here, the component of an indigenous standpoint can be imagining and making in silence [10] - as a socio-political movement, and a preservative tool for Africa's thought rules and language games. Such a concept distinguishes the difference in the logic of sociality and points to ideas about how reframing the concepts of analysing African traditions, cultures, values and language through her contextual forms of making meaning and sense of social life can be re-imagined.

\section{Practical Application for HCI4D Research}

The context for this provocation lies in a philosophical debate that informs empirical research into the design, deployment and use of learning technologies in Nigerian higher education. Although it draws from the context of Nigeria (as a perspicuous setting of Africa), due to shared colonial experience, epistemic exploration and exploitation, and other forms of otherness, it is reasonable to refer to such a positionality as an indigenous 'African' standpoint. Even with the complexities of translating theoretical ideas into practice, the orientation has provided a way of looking at the socio-cultural, educational and linguistic context of Nigeria. It provided access into a set of context-specific ideas, in particular, insights into the perspective of those that inform design, those that design and develop education technologies, and those that get to use them, all of which are shaped by idealised assumptions (often Western) about education and software engineering. It is through the positionality that I have come to adequately articulate the complexities of understanding multiple actors and scenarios, and of making meaning and sense of culture and context for the purpose of design.

\section{Conclusion}

While the ideas of the alternative positionality might not be new, the African standpoint logic is missing in HCI4D literature. As a provocation and possible enlightenment, this paper offers a marginal shift of perspective in understanding the concept of

transcultural ideation and the transnational exchange of innovation right here, right now. It has shown how the standpoint positionality can bring about understanding African values and cultures for the purpose of design.

To develop appropriate and context-specific concepts of understanding the differences and similitude in thought and experience, an analysis of the concept of social rules and language tricks can make sense of and pointing to key insights and attributes of the world better than any theory [12]. Innovative practices can be envisioned when the complex and interweaving formation and orderliness of members' social life is placed centrally in technological discourse, which will help to understand, design, develop, evaluate and deploy technologies in an Africa context. This calls for a sensible outlook towards the discourse of 'HCI4Africa.' 


\section{References}

[1] Abdelnour-Nocera, J., Clemmensen, T., \& Kurosu, M. (2013). Reframing HCI through local and indigenous perspectives. International Journal of Human-Computer Interaction, 29(4), 201-204.

[2] Adamu, M. S. (2019). Designing and Evaluating Learning Technology: An African Dilemma and Approach. In S. Zvacek, H. Lane, \& J. Uhomoibhi (Eds.), In Proceedings of the 11th International Conference on Computer Supported Education: (CSEDU 2019) (Vol. 1, pp. 184-191). SciTePress.

[3] Ali, S. M. (2016). A brief introduction to decolonial computing. XRDS: Crossroads, The ACM Magazine for Students, 22(4), 16-21.

[4] Bardzell, S., \& Bardzell, J. (2011, May). Towards a feminist HCI methodology: social science, feminism, and HCI. In Proceedings of the SIGCHI conference on human factors in computing systems (pp. 675-684)

[5] Bhabha, H. K. (2012). The location of culture. Routledge.

[6] Bidwell, N. J. (2012). Walking together to design. interactions, 19(6), 68-71.

[7] Bidwell, N. J. (2016). Decolonising HCI and interaction design discourse: some considerations in planning AfriCHI. XRDS: Crossroads, The ACM Magazine for Students, 22(4), 22-27.

[8] Collins, P. H. (2002). Black feminist thought: Knowledge, consciousness, and the politics of empowerment. Routledge.

[9] Dell, N., \& Kumar, N. (2016, May). The ins and outs of HCI for development. In Proceedings of the 2016 CHI conference on human factors in computing systems (pp. 2220-2232)

[10] Glenn, C. (2004). Unspoken: A rhetoric of silence. SIU Press.

[11] Gutmann, B. (1935). The African Standpoint. Africa, 8(1), 1-19.
[12] Halverson, C. A. (2002). Activity theory and distributed cognition: Or what does CSCW need to DO with theories? Computer Supported Cooperative Work (CSCW), 11(1-2), 243-267.

[13] Haraway, D. (1988). Situated knowledges: The science question in feminism and the privilege of partial perspective. Feminist studies, 14(3), 575599.

[14] Harding, S., Alcoff, L., \& Potter, E. (1993). Feminist epistemologies. Rethinking Standpoint

[15] Heimgärtner, R. (2013). Reflections on a model of culturally influenced human-computer interaction to cover cultural contexts in $\mathrm{HCI}$ design. International Journal of Human-Computer Interaction, 29(4), 205-219.

[16] Irani, L. C., \& Dourish, P. (2009, February). Postcolonial interculturality. In Proceedings of the 2009 international workshop on Intercultural collaboration (pp. 249-252)

[17] Irani, L., Vertesi, J., Dourish, P., Philip, K., \& Grinter, R. E. (2010, April). Postcolonial computing: a lens on design and development. In Proceedings of the SIGCHI conference on human factors in computing systems (pp. 13111320)

[18] Kapuire, G. K., Cabrero, D. G., Stanley, C., \& Winschiers-Theophilus, H. (2015, December). Framing technology design in Ubuntu: two locales in pastoral Namibia. In Proceedings of the Annual Meeting of the Australian Special Interest Group for Computer Human Interaction (pp. 212-216).

[19] Kumar, C. (2013). Asking We Walk, The South as Political Imaginary. Book Four in the Time of Spring. Bangalore: Streelekha.

[20] Lindtner, S., Bardzell, S., \& Bardzell, J. (2016 May). Reconstituting the utopian vision of making: $\mathrm{HCI}$ after technosolutionism. In Proceedings of the 2016 CHI Conference on Human Factors in Computing Systems (pp. 1390-1402) 
[21] Merritt, S., \& Bardzell, S. (2011). Postcolonial language and culture theory for HCI4D. In $\mathrm{CHI}^{\prime} 11$ Extended Abstracts on Human Factors in Computing Systems (pp. 1675-1680)

[22] Mignolo, W. (2002). The geopolitics of knowledge and the colonial difference. The South Atlantic Quarterly, 101(1), 57-96.

[23] Mignolo, W. D., \& Walsh, C. E. (2018). On decoloniality: Concepts, analytics, praxis. Duke University Press.

[24] San Juan, E. (1998). The Limits of Postcolonial Criticism; The Discourse of Edward Said. Against the Current, 13(5), 28.

[25] Shklovski, I., Lindtner, S., Vertesi, J., \& Dourish, P. (2010, September). Transnational times: locality, globality and mobility in technology design and use. In Proceedings of the 12th ACM international conference adjunct papers on Ubiquitous Computing-Adjunct (pp. 515-518)

[26] Smith, S. (2013). Black feminism and intersectionality. International Socialist Review, 91(11).

[27] Spivak, G. C., \& Harasym, S. (2014). The postcolonial critic: Interviews, strategies, dialogues. Routledge.

[28] Stern, D. G. (2004). Wittgenstein's Philosophical investigations: an introduction (Vol. 2). Cambridge University Press.

[29] Sun, H. (2012). Cross-cultural technology design: Creating culture-sensitive technology for local users. OUP USA

[30] Taylor, A. S. (2011, May). Out there. In Proceedings of the SIGCHI Conference on Human Factors in Computing Systems (pp. 685694).

[31] Tlostanova, M., \& Mignolo, W. (2009). Global coloniality and the decolonial option. Kult, 6(Special Issue), 130-147.
[32] Toyama, K. (2010). Human-computer interaction and global development. Foundations and Trends $₫$ in Human-Computer Interaction, 4(1), 1-79.

[33] Tunstall, E. (2013). Decolonizing design innovation: Design anthropology, critical anthropology, and indigenous knowledge. Design anthropology: theory and practice, 232-250.

[34] Varisco, D. M. (2017). Reading Orientalism: Said and the unsaid. University of Washington Press.

[35] Vázquez, R. (2012). Towards a decolonial critique of modernity. Buen Vivir, relationality and the task of listening. Capital, Poverty, Development, Denktraditionen im Dialog: Studien zur Befreiung und interkulturalität, 33, 241-252.

[36] Wa Thiong'o, N. (1992). Decolonising the mind: The politics of language in African literature. East African Publishers.

[37] Walsh, C. E. (2015). Decolonial pedagogies walking and asking. Notes to Paulo Freire from AbyaYala. International Journal of Lifelong Education, 34(1), 9-21.

[38] Winch, P. (2015). The idea of a social science and its relation to philosophy. Routledge

[39] Winschiers-Theophilus, H., \& Bidwell, N. J. (2013). Toward an Afro-Centric indigenous HCI paradigm. International Journal of HumanComputer Interaction, 29(4), 243-255.

[40] Winschiers-Theophilus, H., Chivuno-Kuria, S., Kapuire, G. K., Bidwell, N. J., \& Blake, E. (2010, November). Being participated: a community approach. In Proceedings of the 11th Biennial Participatory Design Conference (pp. 1-10).

[41] Winschiers-Theophilus, H., Zaman, T., \& Stanley, C. (2017). A classification of cultural engagements in community technology design: introducing a transcultural approach. Ai \& Society, 1-17. 